\title{
University human resources management problems of reality and countermeasures
}

\author{
Chun-Mei Yang ${ }^{1}$ \\ ${ }^{1}$ Management Science and Engineering School, \\ China University Of Geosciences Great Wall College, \\ Baoding, China
}

\begin{abstract}
Now the low utilization rate of the human resources in colleges and universities, which is mainly due to the human resource structure is unreasonable, and the internal mechanism is not sound and the check of choose and employ persons and incentive mechanism is imperfect, and so on.Then we need to improve the university human resources recruitment mechanism,optimizing allocation of human resources in colleges and universities, establishing reasonable university staff performance appraisal system and scientific management mechanism of compensation and benefits from the following aspects, integrating human resources in colleges and universities.
\end{abstract}

Keywords- human resources; employ mechanism; performance assessment; incentive mechanism

\section{Introduction}

Since the 21st century, China's market economy reform process in the speed of fast forward, the key to the development of social and economic resources are people rather than material, therefore, human resource plays a decisive role in the social and economic development. Strengthen the research of university human resources management theory, to carry on the profound changes to the old system which can not adapt to the time, setting up the mechanism of the benign development of human resources in colleges and universities, to promote coordinated development of colleges and universities and the social economy. In

\author{
Xiao-Xian Lv ${ }^{2}$ \\ ${ }^{2}$ Academic Affairs Division, \\ China University Of Geosciences Great Wall College, \\ Baoding, China
}

the process of economic and social development, from innovation, colleges and universities from the aspects of the most basic, can say is involved in each stage of social development, a series of scientific and technological innovation in the work, the maximum pull the rapid development of science and technology and economy. At the same time, also as a human resources gathering place in colleges and universities, the major place to improve the quality of the laborers, and to provide important guarantee for the stability of the social and political order, so to strengthen the human resource management is an indispensable key link, although it is rich in the human resources in colleges and universities, but there are still a lot of problems.

2. The reality of university human resources management problems

2.1 the university human resources structure is not reasonable

Number of teachers and students proportion and imbalance in the structure of teaching staff. In recent years, with the continuous expansion of universities and colleges, the quality and quantity of teaching staff in colleges and universities have made a lot of change, such as table 1 . 
Table 1 in 2013-2020 structure of student-faculty ratios

\begin{tabular}{|c|c|c|c|}
\hline & $\begin{array}{c}\text { The number of } \\
\text { students/growth rate of ten } \\
\text { thousand }\end{array}$ & Rate of increase & full-time teachers \\
\hline 2013 & 2468 & $15.11 \%$ & 149.7 \\
\hline 2020 (estimated) & 2862 & $15.96 \%$ & 204.4 \\
\hline
\end{tabular}

On the one hand, the expansion of college enrollment in recent years, the number of teachers in colleges and universities has from relative surplus to relatively insufficient. On the other hand, the original popular major become a cold major, as the result of some colleges and universities teachers appear relatively surplus.

Table 2 under the age of 40, 1998-2015 teachers proportion and professional title structure

\begin{tabular}{|c|c|c|c|}
\hline & 98 & 09 & 2015 \\
\hline $\begin{array}{c}\text { Under the age of } 40 \\
\text { full-time teachers to total }\end{array}$ & $65.41 \%$ & $69.95 \%$ & $60.88 \%$ \\
\hline Title & number & Proportion & $\begin{array}{c}\text { Proportion of the } \\
\text { average rate of growth }\end{array}$ \\
\hline & 181501 & $14.99 \%$ & $26.29 \%$ \\
\hline Professor & 432356 & $35.7 \%$ & $19.09 \%$ \\
\hline Associate professor & 596954 & $49.3 \%$ & $18.2 \%$ \\
\hline Lecturer & & &
\end{tabular}

There were many unreasonable places in the overall structure of university teachers. From the age structure, the number of elderly teachers proportion is very big. From the title structure, the proportion of professor is small, and accounted to almost half of the proportion of the lecturer. From the degree structure, most of the teachers of colleges and universities who owns high degree is less, highly educated talents evenly distributed, mainly concentrated in the well-known colleges and universities and in big cities. Colleges and universities at the same time there are other contact or excess relatively insufficient, mainly shows: high-end talent, lack of scientific researchers and teachers in ordinary excess; The executive leadership talent lack and grass-roots management personnel surplus;
The structure of university teachers mainly shows in teachers' professional titles and age and other several aspects,which directly reflects the quality of teachers, ability and academic level of the basic situation, and as the quantifiable factors in university teachers, such as in table 2. 
of some colleges and universities discipline, up to $70 \%$, a professor at the post. Common course and some basic courses teachers, the ratio of new discipline professional senior position is too low, formed at the excessive concentration of professor "discipline", and there is no professor "lecturer" unreasonable phenomenon, which has adverse effect on the discipline construction. Its time is useless, because the professional title evaluation of consistent must be hired, and keeps the relevant treatment, post indicator random breakthrough, identity management, on the employment management makes treatment and identity, but with the separation of duties, responsibility, right and benefit of uneven, and it is difficult to realize the implement of assessment, scientific and reasonable allocation.

\subsection{The imperfection of the performance} appraisal mechanism and incentive of colleges and universities

Currently assessment index adopted widely in universities has operated advantages. But too detailed and the amount of absolute indicators, tending to lead teachers and researchers for the length of papers and works and the accumulation of teaching time to struggle. Human resources in colleges and universities need enough time to learn, to track the forefront of the theory, to further practical research,and a high level of teaching achievements also need time to get the accumulation of academic achievements. Comparison is suitable for the quantitative evaluation indexes incentive simple labor, but shall not apply to inspire complex labor.

Because of the influence of traditional ideas, the value of talents in colleges and universities fails to fully reflected,which the incomes of high-level talents and shortage of professional talents in universities and colleges is much lower than the market price, causing brain drain of the implicit and reverse flow of talents, and the appropriate personnel. The school talent incentive is lack of powerful measures. According to the "social" of human resources in colleges and universities, "dynamic" feature, a high level of motivation is necessary. Currently USES the President responsibility system under the leadership of party committees, embodies the management at the university of the Chinese socialist characteristics, but in this system, how to arouse the subjective initiative of the staff, etc., there are still some problems.

\section{The university human resources management strategy \\ 3.1 we will improve the mechanism of university human resources recruitment}

Personnel recruiting and cane to choose as the human resources development and management the most important basic work, it directly affects the reasonable university human resources team formation and the improvement of the competitiveness of colleges and universities. Due to the promotion policies recruitment in colleges and universities, the compensation strategy in universities and colleges of professional security policy and the influence of its own image promotion strategy, which requires colleges and universities related staff during the process of recruitment and selection in accordance with the principles of openness, fairness, strategic orientation, comprehensive. In the process of recruiting related personnel should determine scientific recruitment process that is in turn defined requirements, job analysis, prepared the job description and job qualification requirements and regulations, the recruiting team,to determine the recruitment channels, releasing the recruitment information and including the evaluation of costs and benefits, recruiting time to assess the quantity and quality evaluation of three aspects: the recruitment effect assessment, selecting proper recruitment channels and methods. Due to recruit can be divided into external and internal selection two ways, but because each have advantages and disadvantages, so you need to relevant personnel in colleges and universities considered carefully, in order to avoid the waste of resources. 


\subsection{The optimize allocation of human resources in colleges and universities}

Optimize configuration of university teachers' human resources, should adjust the structure of the following several aspects : First, age structure. Establish a reasonable age structure is the important aspect of human resource structure optimization, only age structure is reasonable, to avoid the emergence of a new age "fault". Second, education structure. To improve teacher education level is one of the important measures to enhance the overall quality and level of business, is also one of the most important aspects of the talent team construction. School should be encouraged to support young teachers through the form of different degrees, to enhance the support for full-time teachers study for a doctorate. Third, academic structure. To build a high level of teacher team, must be diversified, multi-channel from different schools, from the introduction of different degree, different experiences at home and abroad advanced talents, avoiding inbreeding. Fourth, teachers internal structure. Must enrich the teaching scientific research personnel, to streamline the teaching scientific research personnel, compressed non teaching school, expenditure for logistics service personnel and school-run industry personnel executes an enterprise to turn management, to change the actuality that talent shortage and overstaffed, the current situation of human resource utilization efficiency is low.

\subsection{Establish a reasonable university staff performance appraisal system}

Establish scientific performance appraisal system is the basis of the implementation of effective incentive mechanism, whatever incentive should be based on assessment evaluation result, so the practical to build a scientific and reasonable performance evaluation index system is very necessary. The establishment of evaluation index system should consider two aspects, the balance of economic and social benefits, at the same time, to save and care at the forefront of new disciplines, combination of quantitative and qualitative.
In addition to good evaluation, through the simplification, the program according to the characteristics of the post, set some work procedure, open and transparent, to make employees himself completely convinced. Evaluation work refers to people-oriented, comprehensive evaluation,so performance evaluation should pay attention to personal environment, conditions. Single contribution can not decide talents, considering the dual tasks of college talent training and scientific research, to consider whether or not make the development of colleges and universities, department goals and individual performance appraisal target to get together effectively. Performance management is successful or not lying in how to apply performance appraisal results, if the performance review results is used badly,it can make the performance management of employees and ability to reduce performance of incentive.

The result is mainly used in the following aspects: First, for the distribution of the compensation plan and adjustment, which will make the system more fair and objective. Second, used in position, the change of a person through the performance evaluation and feedback, clear its own strengths and weaknesses and suitability for advanced position, so as to facilitate their work. Third, the performance evaluation can provide organizations with the exact situation and the superiority of the overall quality of human resources, staff promotion and the development potential of information, thus conducive to the strategic planning of human resources in colleges and universities. Fourth,it can be used for employee recruitment and selection,which is easy to get true talents for colleges and universities, to cost savings. Fifth, according to the results of the performance evaluation, respectively, meet the needs of employees in training and development, the development of their advantages to the largest extent,which is a disadvantage to minimize, to correctly handle the relationship between internal employees and help them to career planning.

Through the above analysis of the performance 
evaluation of colleges and universities should set up a subsidiary of operation process, so as to make the scientific performance appraisal, rationalization,get the real effective performance evaluation results.

\subsection{Establish a scientific management mechanism of compensation and benefits}

Payment management as a university in the business strategy and development planning guidance, to comprehensively consider the effect of various factors inside and outside college, to determine its own form of payment level, payment structure and the form of payment to wake up the salary adjustment and compensation controlled of the entire process, the role is to attract and retain meet the needs of colleges and universities having a staff, and stimulate their enthusiasm and potential, to help improve the performance of universities and construct good campus culture of colleges and universities. And as a special form of compensation benefits, it is the necessary condition to ensure the personnel in colleges and universities to reproduce, which is to meet the laborer the increasing material and cultural life need the important means, and is a convenient staff meaning a better life, the socialist spiritual civilization and the concrete measures of university cultural construction.

Through the above analysis, which requires colleges and universities to establish a new, scientific and systematic compensation management system as follows: First, pay equal attention to material and spirit, making internal compensation and external compensation perfect combination, to build the construction of comprehensive compensation system. Second, instead of the pure high salary reward, imply comprehensive compensation and employee performance. Third, set up the broadband pay structures, the employee in a job promotion or salary level promotion focusing on personal development and the improvement of ability. Fourth, adopt employee stock option and virtual stock plan, to make employee incentive long-term change and compensation capitalization stock right. Fifth, attach great importance to the compensation and the relationship between the team, to strengthen the organization's ability to work. Sixth, ensure the salary system of transparency and let the staff feel a real fairness and justice. Seventh, adopt flexible and optional welfare, letting staff within the prescribed scope, choosing their own welfare combination. These all need relevant personnel in the compensation system design always be guided by the strategy, meeting the economical principle, the staff value principle, the principle of incentive, the principle of fair competitive principles as well as external.

\section{Conclusion}

College education as the key part of the national talent education, is the guarantee of sustainable development of the country, its teachers' quality determines the quality of college education, and improving the university human resources management is the effective method to improve the quality of teachers staff. In this paper, by analyzing the existing problems in colleges and universities in our country, putting forward by improving the recruitment mechanism, optimizing allocation of human resources, performance evaluation mechanism and compensation mechanism reform of reform measures, improve the utilization efficiency of human resources in colleges and universities.

\section{Reference}

[1] Liu bin. University human resources management problems and countermeasures research [D]. China ocean university, 2012.

[2] Xu Xiaoping. Reasons for the problems existing in the human resource management of university and improvement measures [J]. Journal of Chengde vocational college, 2007, 01:7-9.

[3] Liu Xiaofeng. University human resources management and development present situation analysis and countermeasure research [D]. Hefei University of technology, 2002.

[4] Li Zhenhai. The research of human resource management in colleges and universities in the new era [D]. Northwest university, 2004. 
[5] Yuan Ruijun. Human resource management in colleges and universities study [D]. Zhengzhou university, 2003.

[6] Hai Jie. Colleges and universities teacher human resource management research [D]. Tianjin normal university, 2004.

[7] Ai Xiaoping. The current colleges and universities teacher human resource management research in China [D]. Central China normal university, 2006.
[8] Wang Xin. Incentive problems in the management of human resources research [D]. Northwest university, 2008.

[9] Li Juan. Hubei university human resources management present situation and countermeasure research [D]. Wuhan textile university, 2013 